II

\title{
LYMPHOGRANULOMA INGUINALE (PORADENITIS)
}

\author{
By Dr. N. FAIRLEY ANd DR. H. S. STANNUS
}

\section{Discussion}

DR. LUDWIG KLEEBERG said that after hearing the Papers it was difficult for him to say anything new about Nicolas Favre's disease. The entire literature was to be found in Dr. Stannus's excellent monograph, "The sixth venereal disease."

Having seen more than Ioo cases of lymphogranuloma inguinale, he desired to say a few words about etiology. Hellerström and Wassén were the first successfully to transmit the virus of this disease to monkeys by intracranial inoculation. In I930 he was able to confirm these experiments in conjunction with Cohn in the Robert Koch Institute in Berlin, and to demonstrate that antigen made from the brain of monkeys gave a positive Frei skin reaction in lymphogranuloma inguinale patients. Since then a great deal of experimental work had been done. Recently Tamura in Cincinnati thought he had been successful in cultivating the virus, and D'Aunoy, von Haam, and Liechtenstein of New Orleans believed they had confirmed this. It was of great importance that these findings should be tested once more and on a larger basis. For the diagnosis the reaction of Frei was of the utmost importance, but it must be taken into consideration that Frei's reaction might be negative in the very early stage of the disease and not positive before the allergy had developed. It would be most helpful if Frei's vaccine were always obtainable. In the United States mouse-brain antigen was now commercially prepared and purchasable. By the kindness of his friends Hellerström and Wassén of Stockholm, he always had some samples of Frei antigen in stock, and would be pleased to provide some for any member in need of it.

He proceeded to show a lantern slide of one of his earliest patients who for a long time was being treated 


\section{LYMPHOGRANULOMA INGUINALE}

for tuberculcsis. It showed the characteristic appearance of lymphogranuloma inguinale with fistulæ formation. The intracutaneous reaction of Frei was positive, whereas guinea-pig inoculation for tubercle bacilli was negative. He wished to emphasise that sometimes lymphogranuloma inguinale infection might be possible without any bubo formation; that might often happen in women. $\mathrm{H}_{\mathrm{i}}$, showed a case of elephantiasis vulvæ which gave a positive Frei reaction, but in which there was at no time a bubo. On examining partner cases he also found women without any signs of disease, only with positive Frei. He believed the situation to be similar to that of the soft chancre infection, in which he found, while examining a woman whose partner had a soft chancre, no signs at all of the disease in the cervix, only a positive Reenstierna ulcus molle reaction.

Referring to the various skin manifestations of lymphogranuloma inguinale, he showed some slides of erythema nodosum with aphthæ on the genitalia. He had seen 7 cases of elephantiasis vulvæ and stricture of the rectum, but not all cases of elephantiasis vulvæ were caused by lymphogranuloma inguinale. He showed one slide of this condition caused by soft chancre in which Frei's intracutaneous reaction was negative, and the Dmelcos reaction always positive.

The primary infection in lymphogranuloma inguinale was known to be very often located in the urethra, because a urethritis was a characteristic early symptom, therefore it was not surprising that a stricture of the urethra might develop. He showed a slide of stricture of the front part of the urethra with formations of two fistulæ on the sulcus coronarius. Frequent examinations for gonorrhœa by smears and culture were without any result. A complement-fixation test was negative, as were the Dmelcos reaction, and the inoculation of guineapigs to tubercle bacilli. Frei's intracutaneous reaction with four different antigens was always positive.

So far there was no ideal treatment. Some cases improved or were cured simply by resting in bed, but as a rule they were more complicated. He had seen good results after intracutaneous tuberculin treatment, also with gold (solganal oleosum). Hellerström had observed good results with intravenous antigen treatment, but the speaker had no experience in that direction. 


\section{BRITISH JOURNAL OF VENEREAL DISEASES}

Mr. Ambrose King said that he was diffident about taking part in the discussion when so much valuable information had been presented by experts in this subject. It had, however, been suggested that the experiences of clinic medical officers might be of some interest, since it was thought by some that an increasing number of cases of this infection were likely to be found in venereal disease clinics.

On the few occasions that he had been fortunate enough to see the primary lesion, this had taken the form of a papule surmounted by a vesicle, and he would be interested to know whether this was the usual appearance.

Although at the Whitechapel Clinic a good many patients were drawn from the dockland area, few of those suffering from lymphogranuloma inguinale came from that district, nor had they had relations with dockland prostitutes.

On the other hand, he could remember two who were agricultural labourers from the country, and in these, as in most of the other cases, the incubation period had been long and the disease had taken a mild course. Glandular enlargement had been limited to the Inguinal groups without apparent enlargement of the iliac glands. The number of cases seen in a year was 4 or 5, and they appeared to clear up without any active treatment. Suppuration sometimes occurred, but usually aspiration of the abscesses on two or three occasions was sufficient to establish any drainage that was necessary.

It was even more rare to see female patients with this infection in clinic practice. He could recall only two in which the diagnosis was suspected, and in both of these Frei's test had been negative.

It had been noticed on a number of occasions that casès showing the typical appearances had given a negative response with Frei's antigen. When they had been fortunate enough to obtain the antigen direct from Dr. Stannus, the results of the test had accorded with the clinical findings.

Dr. David Nabarro said that he had not much in the way of personal experience to relate with regard to this disease. A few weeks ago he saw a female child five weeks old with a peculiar vaginal discharge and a peculiar condition of the external genitalia, a good deal of super- 


\section{LYMPHOGRANULOMA INGUINALE}

ficial ulceration at the posterior part of the external genitals. There were two quite large inguinal glands, and thinking of the possibility of lymphogranuloma inguinale, he rang up Dr. Marshall Findlay, who aspirated one of the glands and took some of the pus for investigation and did a Frei's test. The Frei's test turned out to be negative, and the pus he injected into animals proved a tuberculous condition. A further examination showed other things pointed to tuberculosis, and there was a history of tuberculosis in the mother. But in all his experience at Great Ormond Street he had never seen a case quite like that; he showed a couple of photographs.

He wondered in how many cases the authors would estimate the Wassermann reaction to be positive in lymphogranuloma inguinale. It was just possible that a mixed infection would modify the lesions produced. Were the lesions different in lymphogranuloma per se from what they were in a combined infection?

Dr. T. E. Osmond said that he had been interested in what had been stated about the failure of some of the antigens. He had seen a case recently which he thought was perfectly typical. It was a case of a soldier just home from abroad. He had glands in both groins, which did not look in the least like breaking down. A Frei test was done, but to his great disappointment it was negative. $\mathrm{He}$ wondered whether the explanation was that the antigen was inefficient. With regard to antigens made from mouse-brain, it appeared proved by American workers that the mouse-brain antigen was most unreliable. It might give false positive reactions or false negative reactions. Antigen from normal mouse-brain might give a positive reaction in a case that was not true lymphogranuloma. He wondered whether an antigen made from monkey-brain was similarly unreliable.

With regard to treatment, they were told that operation was very successful in early cases. But what was an early case? Up to what point should one operate, and after what point was operation likely to be unsuccessful ? If a comparatively late case were operated on, or an extensive operation done on any case, might not the result be to cause elephantiasis itself by cutting off the lymphatic channels or blocking them ?

Colonel L. W. Harrison (from the Chair) referred to the incidence of the disease in this country. Dr. Stannus 


\section{BRITISH JOURNAL OF VENEREAL DISEASES}

had said some few years ago that he thought it was being overlooked. Accordingly a very close look-out had been kept for cases at the St. Thomas's Hospital Clinic, but since that earlier discussion at the Royal Society of Tropical Medicine they had not seen more than half a dozen cases. One of these had been sent to him as a case of gonorrhœal proctitis in a young man, but he had come to the conclusion that most probably it was a case of lymphogranuloma inguinale, as there was a rectal stricture and all tests for gonococcal and syphilitic infection were negative. The Frei test proved quite strcngly positive while the Dmelcos skin test was negative. The symptoms in that case, apart from the stricture, cleared up completely under iodoform suppositories and intravenous injections of Dmelcos. Another interesting case was that of a patient who came for some other trouble and was found to have an elephantoid condition of the penis and scrotum. When inquiries were made into his past history it turned out that twenty-eight years ago he had had a chronic enlargement of inguinal glands. He was stationed in Ireland at the time and was sent over to St. Thomas's Hospital in London where Sir Charles Ballance removed the affected glands. His reaction to the Frei test after this long time was positive.

It was interesting to hear and read about the number of materials which had been employed as antigens in the skin test. For example, if he remembered rightly, Dr. Kleeberg had reported positive Frei reactions with antigen made of fluid from blisters over the lesions of the erythema nodosum which had occurred in some of his cases of L.i. He had been especially interested to read some time ago that the urethral discharge from that type of urethritis which was known to workers in this country as "sago-grain" urethritis and to others apparently as Waelch urethritis gave positive reactions when used as antigen in cases of L.i. Was it because Waelch urethritis was due to an allied organism or because cases of L.i. would react to a number of nonspecific antigens?

He also asked whether any work had been done at the Hospital for Tropical Diseases on culture of the virus or to develop a complement-fixation test as had been done by Coutts in Chili. It would also be a good thing if the proper name of this condition could be settled. Was 


\section{LYMPHOGRANULOMA INGUINALE}

it the fourth venereal disease or the sixth ? He always referred to it as the sixth, but some workers called it the fourth, and that led to confusion.

Dr. Stannus, in reply, agreed with the Chairman that something ought to be done about the nomenclature. He had used the term " sixth venereal disease," but he had been careful to say, not the sixth, but $a$ sixth. Here was a disease which did in the majority of cases affect the glands, and therefore might be called adenitis, but, on the other hand, there were some conditions pertaining to this infection in which no glands at all were affected. Some such term as "poradenitis" or "poradenolymphitis" might be best.

With regard to the disease in children, a limited number of cases had been published.

As for extra-genital infections, there could, of course, be infection in any part of the body, and a certain number of cases were on record of surgeons and nurses who had been infected on the fingers; the primary lesion might be in the mouth with adenitis in the neck.

The occurrence of cases among agricultural labourers was certainly most interesting. Up to date the only 3 cases which had come under his care in this country had probably all been infected by the same woman, a London prostitute. It would be interesting to discover her and learn what exactly was her condition. In Barcelona, where the disease was not uncommon, it was held that there were what might be called "carrier cases."

A case had been published not long ago in which a mother had infected her child by means of an enema which she, herself, suffering from rectal stricture, had used.

The difficulty about antigens was that many were unsatisfactory, but if Frei's original technique was: followed, he thought the test a good one.

Dr. FAIRLEY, also in reply, said that he could only answer the question about the primary lesion in terms of the literature, and say that these primary papules might become vesicular or pustular. The question as to the effects of syphilis on the course of virus infection he could not answer definitely, but his impression was that the actual bubo ran much the same course, whether the blood was Wassermann positive or Wassermann: 


\section{BRITISH JOURNAL OF VENEREAL DISEASES}

negative. That, however, was only an impression. Monkey-brain extracts had been used as antigen, but it had not been stored and subsequently tested as far as he knew in the same way as the mouse-brain antigen. The fact that mouse-brain antigen on keeping developed the property of producing positive reactions in normal people was most disquieting.

Regarding the right time to excise glands, the most dramatic cures he had seen had followed excision in the early stages. He thought it would be entirely wrong to excise the glands once sinuses had formed and where there was extensive involvement of the crural glands. One case at the Hospital for Tropical Diseases had developed elephantiasis of the leg following operation; in that case the operation was an extensive one, both superficial and deep glands having been removed. 